\title{
Uterine torsion in a case of previous two caesarean section mimicking uterine rupture: a case report
}

\author{
Priti Agrawal $^{1 *}$, Rishi Agrawal' ${ }^{2}$ Jyotirmay Chandrakar ${ }^{3}$
}

\begin{abstract}
${ }^{1}$ Department of Obstetrics, Gynecology and Infertility, ${ }^{2}$ Department of General and Laparoscopic Surgery, ${ }^{3}$ Department of Anesthesia, Aarogya Hospital and Test Tube Baby Center, Raipur, Chhattisgarh, India
\end{abstract}

Received: 22 December 2020

Revised: 01 February 2021

Accepted: 02 February 2021

\author{
*Correspondence: \\ Dr. Priti Agrawal, \\ E-mail: drpritiagrawal15@gmail.com
}

Copyright: (C) the author(s), publisher and licensee Medip Academy. This is an open-access article distributed under the terms of the Creative Commons Attribution Non-Commercial License, which permits unrestricted non-commercial use, distribution, and reproduction in any medium, provided the original work is properly cited.

\begin{abstract}
Uterine torsion (UT) is defines as a rotation of the uterus of more than 45 degree on its long axis. The predisposing factors for UT can be uterine asymmetry due to fibroids or mullerian anomalies, foetal malpresentation, pelvic adhesions and abdominal or ligamentous laxity other possible causes include external cephalic version, maternal trauma and abdominal massage. The clinical presentation of UT is non-specific. We report a case of previous 2 CS where we suspected rupture uterus but intraoperatively it was UT with unruptured fibrosed scar of previous CS. A 31 years old, G3P2 presented in emergency department with history of amenorrhea 9 months and severe abdominal pain for 5-6 hours. She had previous 2 CS done for contracted pelvis. We immediately suspected rupture of previous CS scar. On laparotomy dense intra-abdominal adhesions were found. After adhesiolysis we could find any sign of previous scar on the visible uterine wall. Entire uterine wall seemed as if we were doing CS in a primiparous patient. This made us suspicious of UT. UT is considered rare and has been referred to as an 'obstetrician's once in a lifetime diagnosis'. Recently cases have been reported with no associated pelvic factors although a common feature in all these cases had been previous CS. UT is a potentially dangerous complication of pregnancy both to the mother and to the foetus. Maternal mortality in modern era highly unexpected event but maternal morbidity can occur because of complications like uterine rupture, uterine abruptio, sepsis, pulmonary embolism and iatrogenic complications like injury to blood vessels, urinary tract and rectum. During laparotomy where correction of UT is not possible, a deliberate posterior hysterotomy can be done for delivery of foetus. Bilateral plication of the round ligaments can be done to prevent immediate postpartum recurrence of UT. UT though rare should be kept in mind while performing CS in cases of previous CS, associated myomas, ovarian tumour, malpresentations of foetus. Clinical symptoms may be absent or nonspecific and the diagnosis may be intraoperative.
\end{abstract}

Keywords: Uterine torsion, Caesarean section, Abdominal pain, Laparotomy

\section{INTRODUCTION}

Uterine torsion (UT) is defines as a rotation of the uterus of more than 45 degree on its long axis. UT is rare and its incidence and prevalence is not well known. Majority of cases of UT are associated with pregnancy, often asymptomatic and only found during caesarean section (CS). The condition can occur in all ages, all parity and in any ages, all parity and in any trimester of pregnancy.
The predisposing factors for UT can be uterine asymmetry due to fibroids or mullerian anomalies, foetal malpresentation, pelvic adhesions and abdominal or ligamentous laxity other possible causes include external cephalic version, maternal trauma and abdominal massage. The clinical presentation of UT is non-specific. The most common symptom is abdominal pain varying from non- specific mild abdominal discomfort to severe abdominal pain with shock. ${ }^{1}$ In some cases the diagnosis 
is made after delivery of foetus. When the repair of CS incision is noted to be very vascular. The uterine incision is sometimes inadvertently made on posterior or lateral wall due to the location of the uterus. ${ }^{2,3}$

We report a case of previous $2 \mathrm{CS}$ where we suspected rupture uterus but intraoperatively it was UT with unruptured fibrosed scar of previous CS.

\section{CASE REPORT}

A 31 years old, G3P2 presented in emergency department with history of amenorrhea 9 months and severe abdominal pain for 5-6 hours. She had previous 2 CS done for contracted pelvis. We immediately suspected rupture of previous CS scar. Her vitals were stable. On per abdomen examination uterine fundal weight was 36 weeks and vague tenderness in all quadrants of abdomen was noted. Foetal heart sounds were normal. On per vaginum examination, cervix was uneffaced and not dilated. Pelvis was contracted. On ultrasonography a viable foetus of 36 weeks in variable presentation was seen. Expected foetal weight was $3.1 \mathrm{~kg}$. Previous CS thickness was normal and placenta was fundal. No heamoperitoneum or intra-abdominal cause for acute abdomen was found.

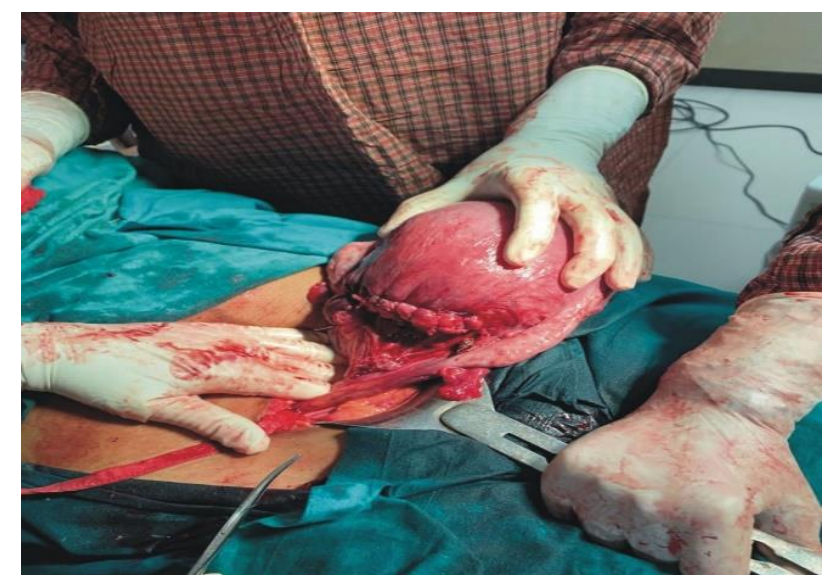

Figure 1: Dextrorotated uterus showing posterior uterine wall incision with repair.

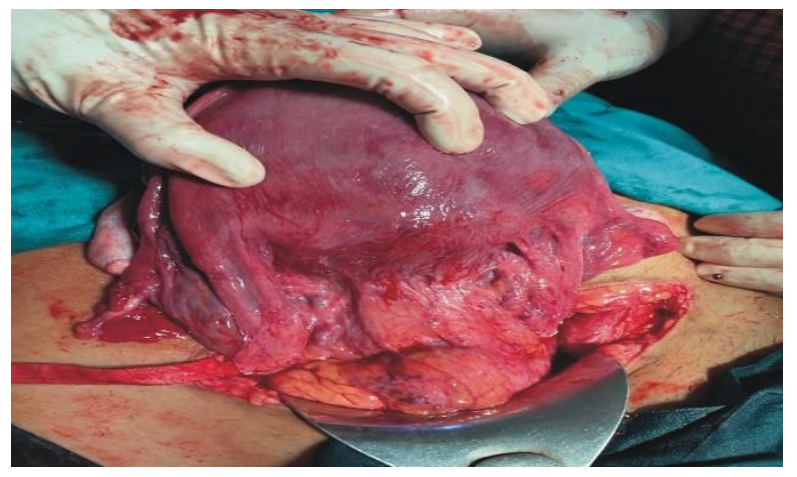

Figure 2: Previous 2CS scar identified on anterior uterine surface because of indentation.

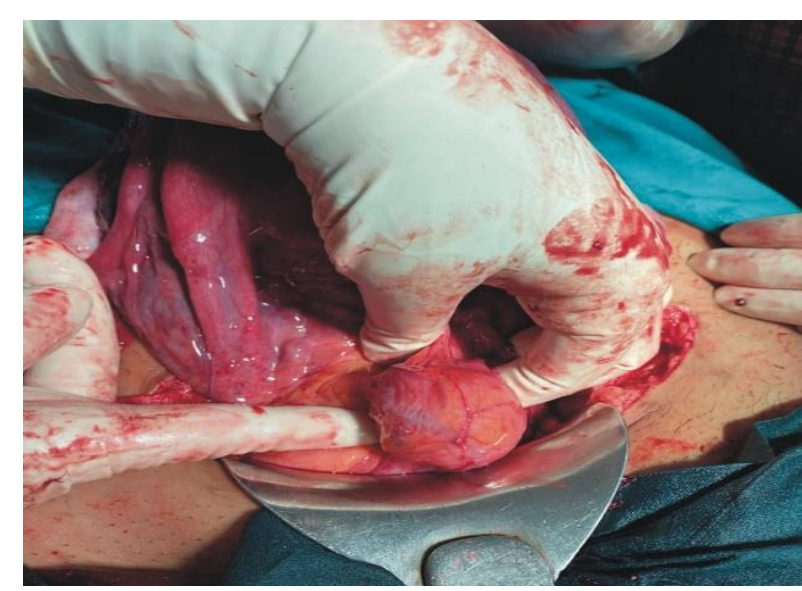

Figure 3: Bladder lower down with foley's catheter insitu.

On laparotomy dense intra-abdominal adhesions were found. After adhesiolysis we could find any sign of previous scar on the visible uterine wall. Entire uterine wall seemed as if we were doing CS in a primiparous patient. This made us suspicious of UT. Dextrotation tried but could not achieved due to full term foetus and previous adhesions. Hence deliberate transverse incision given on posterior uterine wall. After delivery of foetus \& placenta, uterus exteriorised, torsion of 180 degree corrected and repair of incision done (Figure 1) Previous CS scar was thick and identified only because of depression on the uterine wall (Figure 2).

And intact bladder lower down with foley's catheter insitu (Figure 3). Bilateral plication of the round ligaments was done. Adequate haemostasis was achieved with no difficulty. Bilateral tubectomy was done. Baby weighed 3 kilograms with Apgar score of 10 . Postoperative recovery was uneventful.

\section{DISCUSSION}

UT is considered rare and has been referred to as an 'obstetrician's once in a lifetime diagnosis'. Pregnancy exaggerates the congenital and physiologic rotations and obliquities of the uterus making the gravid uterus prone for UT, though cases have also been reported in nongravid uteri. ${ }^{4,5}$

Recently cases have been reported with no associated pelvic factors although a common feature in all these cases had been previous CS. This may be because of poor isthmic healing resulting in suboptimal restoration of normal cervical length leading to an elongated cervix with structural weakness and angulation in the isthmic region leading to torsion. Most case of UT present with abdominal pain but signs and symptoms may be variable and about $11 \%$ of patients may remain asymptomatic 6 . Uterine torsion if detected remote from term then urgent laparotomy and rotation of uterus into its normal anatomical position may give chance for normal course of pregnancy. ${ }^{7}$ UT presenting in labour may manifest by 
failure of cervical dilatation despite strong uterine contraction or foetal distress due to reduction in uterine blood flow. UT is a potentially dangerous complication of pregnancy both to the mother and to the foetus. Maternal mortality in modern era highly unexpected event but maternal morbidity can occur because of complications like uterine rupture, uterine abruptio, sepsis, pulmonary embolism and iatrogenic complications like injury to blood vessels, urinary tract and rectum.

During laparotomy where correction of UT is not possible, a deliberate posterior hysterotomy can be done for delivery of foetus. Both vertical and transverse posterior uterine incision have been described. The risk of rupture of posterior transverse incision is theoretically less than a posterior vertical incision, although exact risk is not known because of the rarity of this condition. After delivery manual correction can be easily performed and associated pathologies like adhesions, fibroids or ovarian cysts should be removed to prevent recurrence.

Bilateral plication of the round ligaments can be done to prevent immediate postpartum recurrence of UT. This keeps the uterus in anteversion, prevents posterior uterine adhesions and future dyspareunia. Bilateral plication of uterosacral ligaments has also been described. ${ }^{8,9}$

The perinatal mortality has been reported to be about $12 \% .^{6}$ The perinatal mortality was $20 \%$ for torsion less than 90 degree and $83 \%$ for torsion more than 360 degree. Uterine venous obstruction due to UT causes increased pressure in placental cotyledons resulting in abruptio placentae foetal distress and foetal demise.

\section{CONCLUSION}

UT though rare should be kept in mind while performing $\mathrm{CS}$ in cases of previous CS, associated myomas, ovarian tumour, malpresentations of foetus. Clinical symptoms may be absent or nonspecific and the diagnosis may be intraoperative. Anatomical landmarks should always be defined prior to uterine incision during a CS to prevent damage to uterine vessels and vital organs. Early diagnosis and laparotomy may help to reduce maternal and perinatal mortality and morbidity.

Funding: No funding sources

Conflict of interest: None declared

Ethical approval: Not required

\section{REFERENCES}

1. Mokhtar H N, Faridz S M, Ismail R, Yaacob N, Ramli R, Uterine torsion in pregnancy, expect the unexpected: case report, Int J Reprod Contracept Obstet Gynecol. 2020;9(8):3473-6.

2. Farhadifar F, Nikkhoo B, Shahgheibi S, Soofizadeh N, Rezaie M, Asymptomatic Uterine Torsion in a Pregnant Woman, Indian J Surg. 2014;76(4):321-2.

3. Moores KL, Wood MG, Foon RP. A rare obstetric emergency: acute uterine torsion in a 32-week pregnancy, Bio Med J Case Rep. 2014:2013202974.

4. Ho PL, Hameed MSBS, Chern B, A Rare Case of Complete Uterine Torsion in a Postmenopausal Woman. J Med Cases. 2019;10(6):164-7.

5. Halassy S, Clarke D, Twisting around an axis: A case report of uterine torsion, Case Reports in Women's Heal. 2020;25:e00170.

6. Jenson JG. Uterine torsion in pregnancy. Acta Obstet Gynecol Scand. 1992;71:260-5.

7. Kopko J, Stańczak R, Warzecha D, Wielgos M, Uterine torsion in the second trimester of pregnancy. 2019;39(6):423-6.

8. Mustafa MS, Shakeel F, Sporrong B. Extreme torsion of the pregnant uterus. Aust NZ J Obstet Gynaecol. 1999;39:360-3.

9. Dua A, Fishwick K, Deverashetty B, Uterine Torsion in Pregnancy: A Review. J Gynecol Obstet. $2005 ;(6) 1: 1$.

Cite this article as: Agrawal P, Agrawal R, Chandrakar J. Uterine torsion in a case of previous two caesarean section mimicking uterine rupture: a case report. Int J Reprod Contracept Obstet Gynecol 2021;10:1169-71. 